\title{
Mechanistic Studies of the Oxidative Addition of Aryl Halides to Ni(0) Centers Bearing Phosphine Ligands
}

\author{
Pablo Marcelo Pérez-García and Marc-Etienne Moret*
}

\begin{abstract}
The oxidative addition of aryl halides is a common entry point in catalytic cycles for cross-coupling and related reactions. In the case of phosphine-supported nickel( $(0)$ fragments, the formation of reactive $\mathrm{Ni}(\mathrm{II})$-aryl products often competes with the production of $\mathrm{Ni}($ (I) species. Here, recent advances in the mechanistic understanding of these reactions are highlighted. In particular, the denticity of the supporting ligand has a significant influence on the outcome of the reaction.
\end{abstract}

Keywords: Cross-coupling $\cdot$ Nickel $\cdot$ Oxidative addition $\cdot$ Phosphine ligands $\cdot$ Reaction mechanisms

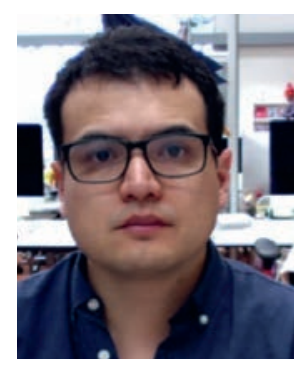

Pablo Marcelo Pérez-García received his BSc and MSc degrees from the University of Geneva in 2006. After working for some years in several universities in his home country Bolivia, he moved to Lausanne to work with Prof. Xile Hu at EPFL on the development of well-defined cross-coupling nickel catalysts, where he received his $\mathrm{PhD}$ degree in 2015 . From 2018 on, he is a postdoctoral researcher at Utrecht University with Dr. Marc-Etienne Moret. His current main research is focused on the fundamental understanding of the reaction steps for cross-coupling process.

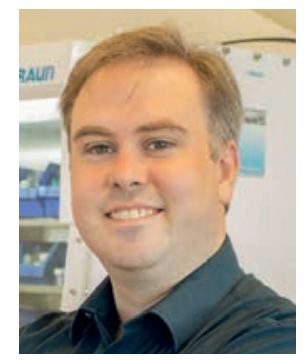

Marc-Etienne Moret obtained an MSc degree in chemistry from EPFL in 2005, and a $\mathrm{PhD}$ degree from ETHZ with Prof. P. Chen in 2009. In 2010, he moved to the California Institute of Technology (Caltech) for postdoctoral research in the group of Prof. J. C. Peters on the activation of $\mathrm{N}_{2}$ by synthetic iron complexes. Since 2012, he is assistant professor at Utrecht University (UU). His research interests revolve around the design of ligands for small-molecule activation and catalysis using firstrow transition metals.

\section{Introduction}

The oxidative addition of aryl halides to a reduced metal center is often the activation step through which these substrates enter the catalytic cycle of cross-coupling reactions. ${ }^{[1]}$ A fundamental mechanistic understanding of this reaction is crucial for the rational development of more efficient cross-coupling catalysts. While the field of transition-metal catalyzed cross-couplings is dominated by palladium catalysis, ${ }^{[2]}$ nickel is an attractive alternative for reasons that are not limited to sustainability. Oxidative addition to a $\mathrm{Ni}(0)$ center is generally easier even for challenging bonds as $\mathrm{C}-\mathrm{O},{ }^{[3]}$ due to its lower reduction potential and lower electronegativity. ${ }^{[4]}$ Another innate characteristic of nickel is the more facile accessibility of open-shell electronic configurations as $\mathrm{Ni}(\mathrm{I})$ and $\mathrm{Ni}(\mathrm{III})$, because of a higher electron pairing energy due to a smaller nucleus radius when compared to palladium. ${ }^{[4]}$ The latter characteristic allows nickel to react through singleelectron transfers; ${ }^{[5]}$ depending on the reaction, these pathways can be either productive ${ }^{[6]}$ or detrimental, ${ }^{[7]}$ leading in that case to off-cycle species and/or byproducts. ${ }^{[8,9]}$ Generally speaking, the competition between several pathways can be modulated by the surrounding ligands, ${ }^{[6]}$ and an understanding of the relationship between the ligand structure and the branching ratio between different pathways is desirable.

Phosphine donor ligands occupy a place of choice in nickelcatalyzed cross-coupling methodologies because of their soft character, allowing them to stabilize reduced $\mathrm{Ni}(0)$ intermediates. ${ }^{[10]}$ In a simplified catalytic cycle (Scheme 1), the reaction of an aryl halide with a $\mathrm{Ni}(0)$ center bearing phosphine ligands affords $\mathrm{Ni}$ (II) aryl halide complexes, which then undergo transmetallation with a carbon nucleophile and reductive elimination to generate the coupling product and regenerate the active $\mathrm{Ni}(0)$ complex. ${ }^{[4]}$ However, $\mathrm{Ni}$ (I) species are often observed both in stoichiometric reactions and under catalytic conditions. ${ }^{[7,11]}$ While Ni(I) species are thought to be involved as catalytically competent intermediates with several $N$ - and $C$-donor supporting ligands, ${ }^{12]}$ evidence suggests that they are off-cycle species in $P$-donor systems. ${ }^{[8,9]} \mathrm{In}$ this short account, we present some relevant recent mechanistic studies on the oxidative addition of aryl halides to a $\mathrm{Ni}(0)$ center bearing phosphine ligands. The stability in solution of $\mathrm{Ni}$ (II) aryl halide complexes and the selectivity ratio between $\mathrm{Ni}(\mathrm{II}) / \mathrm{Ni}(\mathrm{I})$ species are discussed, as well as the influence of the denticity of the supporting phosphine ligands. In particular, the ability of a tridentate PPP pincer ligand to favor clean oxidative addition to $\mathrm{Ni}(0)$ to form stable 5-coordinate aryl-Ni(II) was studied experimentally and computationally as a collaboration between Utrecht University and KU Leuven (A. Darù, Prof. J. N. Harvey), facilitated by the NoNoMeCat Network.

\section{Monodentate Phosphine ligands}

Early on, the reaction of para-substituted aryl halides with $\left(\mathrm{PEt}_{3}\right)_{4} \mathrm{Ni}^{0}$ complex was studied in detail by Kochi and coworkers. ${ }^{[13]}$ They suggested that, after the dissociation of one ligand, an electron transfers from the nickel center to the aryl halide to 


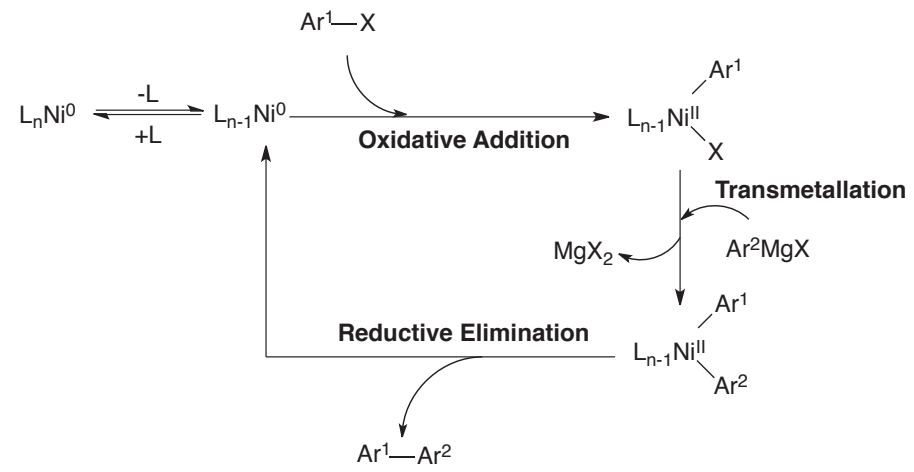

Scheme 1. Simplified two-electron catalytic cycle for an aryl-aryl crosscoupling reaction catalyzed by a $\mathrm{Ni}(0)$ complex.

form a solvent-caged radical ion pair $\left[\mathrm{Ni}^{\mathrm{I}}\left(\mathrm{PEt}_{3}\right)_{3}{ }^{+} \mathrm{ArX} \mathrm{X}^{-}\right]($Scheme 2). This intermediate can decay in two ways: either (1) the aryl radical is trapped by the $\mathrm{Ni}(\mathrm{I})$ center to form the $\mathrm{Ni}$ (II) oxidative addition product $\left[\mathrm{Ni}^{\mathrm{II}}\left(\mathrm{PEt}_{3}\right)_{2}(\mathrm{Ar}) \mathrm{X}\right]$, or $(2)$ the aryl radical diffuses out of the solvent cage, ultimately abstracting an $\mathrm{H}$-atom from the solvent, and the Ni(I) complex $\left[\mathrm{Ni}^{\mathrm{I} X}\left(\mathrm{PEt}_{3}\right)_{3}\right]$ is formed. The $\mathrm{Ni} / \mathrm{Ni}^{\mathrm{II}}$ ratio decreased with increasing $\mathrm{C}-\mathrm{X}$ bond strength, with lower polarity solvents, and with electron withdrawing substituents on the aryl moiety. Similar competition between Ni(I) and $\mathrm{Ni}$ (II) production have been observed with different phosphine ligands. An additional complication arises from the fact that the formed $\mathrm{Ni}$ (II)-aryl species can decay to $\mathrm{Ni}$ (I) via bimetallic reductive elimination as recently described by Baird and Budzelaar[14] in the case of trans- $\mathrm{Ni}\left(\mathrm{PPh}_{3}\right)_{2}(\mathrm{Ph}) \mathrm{Cl}$.

These experimental results were recently slightly reinterpreted in computational studies by Maseras and coworkers (Scheme
3). ${ }^{[15]}$ Instead of the common intermediate $\left[\mathrm{Ni}^{\mathrm{I}}\left(\mathrm{PR}_{3}\right)_{3}^{+} \mathrm{ArX}-{ }^{-}\right]$proposed by Kochi, they proposed two parallel reaction pathways: (1) the formation of $\left[\mathrm{Ni}^{\mathrm{II}}\left(\mathrm{PR}_{3}\right)_{2}(\mathrm{Ar}) \mathrm{X}\right]$ goes through a bimolecular, $\mathrm{S}_{\mathrm{N}}$ 2-like oxidative addition mechanism, and (2) the formation of $\left[\mathrm{Ni}{ }^{\mathrm{I}} \mathrm{X}\left(\mathrm{PR}_{3}\right)_{3}\right]$ goes through a halogen atom abstraction mechanism passing by an open-shell singlet transition state. The activation energies for the halide abstraction mechanism increase with the energies of the $\sigma^{*}$ orbitals for the carbon halide bonds in the aryl halide substrates. These results match well with the experimental observations reported by Kochi. The chemical nature of the halide seems to be not relevant for the value of the activation energy for the $\mathrm{S}_{\mathrm{N}}$ 2-like oxidative addition mechanism. On the other hand, the number of phosphines bound to the nickel center showed to be relevant for the oxidative addition mechanism, a tris(phosphine) complex being necessary for energetically accessible transition states.

\section{Bidentate Phosphine Ligands}

Bidentate phosphine ligands generally form more stable adducts because of the chelate effect and are often applied in Nicatalyzed cross coupling reactions. The reactions of aryl halides with a $\mathrm{Ni}(0)$ center bearing a bidentate phosphine ligand also yield $\mathrm{Ni}$ (II) aryl halide complexes and $\mathrm{Ni}$ (I) species in a ratio that strongly depends on the chosen ligand. For example, electron-rich diphosphines such as dippe (dippe = 1,2-bis(diisopropylphosphino) ethane $)^{[16]}$ and dcpp (dcpp $=1,3$-bis(dicyclohexylphosphino) propane $)^{[17]}$ led to the exclusive formation of well-defined $\mathrm{Ni}$ (II) aryl halide complexes, as does the narrow bite angle diphosphine BINAP (2,2'-bis(diphenylphosphino)-1,1'-binaphthyl). ${ }^{[8]}$ On the other hand, when the wide angle diphosphine XantPhos is used, only $\mathrm{Ni}(\mathrm{I})$ halide species are obtained. ${ }^{[18]}$

Nelson and coworkers studied in detail the mechanism of the reaction of ortho- and para-substituted aryl halides with the
Scheme 2. Kochi's mechanism proposing the solvent-caged radical ion pair $\left[\mathrm{Ni}^{\prime}\left(\mathrm{PEt}_{3}\right)_{3}{ }^{+} \mathrm{ArX} \mathrm{X}^{-}\right]$as a common intermediate.

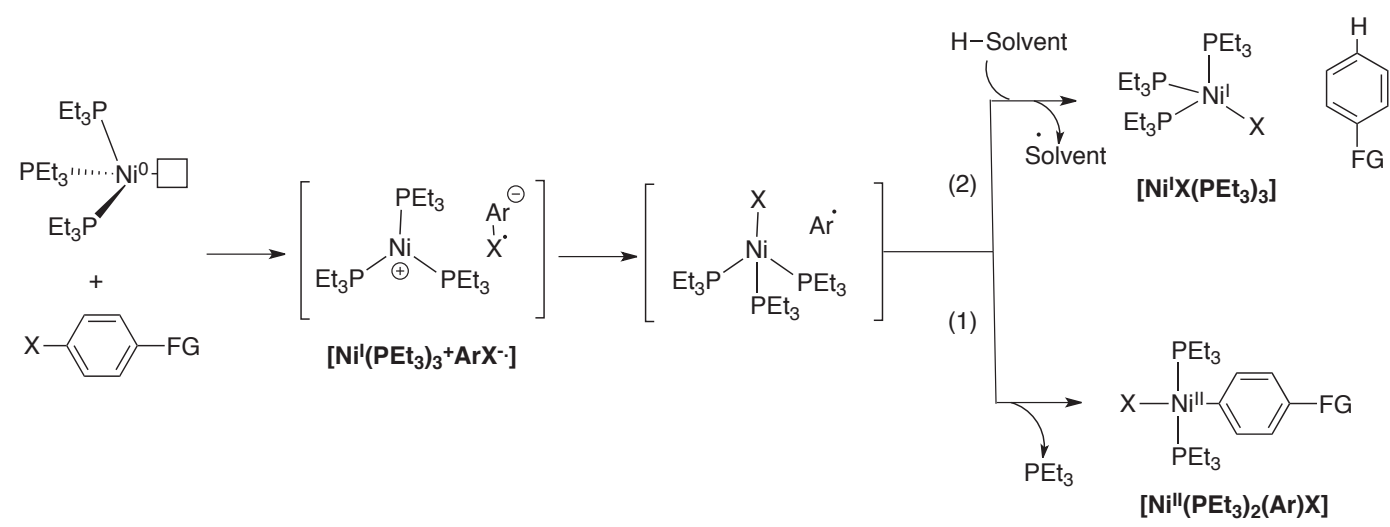

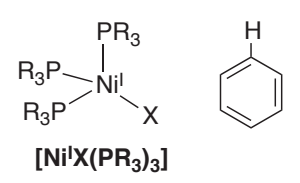<smiles>[Y][N+](P)(P)c1ccccc1</smiles>

$\left[\mathrm{Ni}^{\mathrm{Il}}\left(\mathrm{PR}_{3}\right)_{2}(\mathrm{Ar}) \mathrm{X}\right]$
Scheme 3. Maseras's proposal suggesting two parallel mechanisms: halogen atom abstraction and oxidative addition.

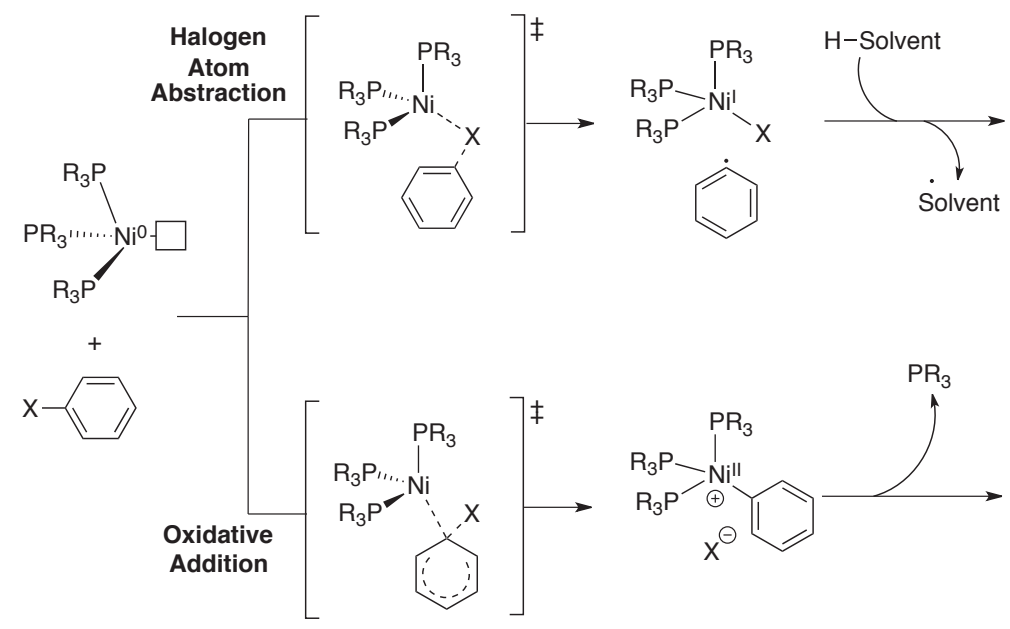


well-defined (dppf) $\mathrm{Ni}^{0}(\mathrm{COD})$ complex. ${ }^{[19]}$ They proposed a fast exchange preequilibrium between the COD and the aryl halide, followed by the oxidative addition going through a three-center concerted transition state leading to the formation of (dppf) $\mathrm{Ni}^{\mathrm{II}}(\mathrm{Ar}) \mathrm{X}$ complexes (Scheme 4A). This proposal was supported by a nil experimental activation entropy and a small positive rho value $(\rho=1.15)$ determined by Hammett analysis. Complexes (dppf)NiII (Ar)X are short-lived and only observable when orthosubstituted aryl halides are used as substrates, presumably due to steric stabilization (ortho effect). ${ }^{[20]}$ They are unstable in solution due to their fast reaction with unreacted (dppf) $\mathrm{Ni}^{0}(\mathrm{COD})$, leading to the formation of (dppf) $\mathrm{Ni}^{\mathrm{I}} \mathrm{X}$ and (dppf)Ni $\mathrm{Ni}^{\mathrm{I}}(\mathrm{Ar})$ by comproportionation (Scheme 4B). The authors suggest that complexes (dppf) $\mathrm{Ni}^{\mathrm{I}}(\mathrm{Ar})$ regenerate the complex $(\mathrm{dppf}) \mathrm{Ni}^{0}(\mathrm{COD})$, either by a sequence disproportionation - reductive elimination or a hydrogen atom abstraction from the solvent..$^{[9,10]}$ the reaction suggested an equilibrium between the coligand BPI and the aryl halide, followed by a concerted oxidative addition process passing by a polarized transition state. The nature of the transition state is supported by an experimental negative entropy of activation $\left(-18(2) \mathrm{cal} \mathrm{K}^{-1} \mathrm{~mol}^{-1}\right.$ ) and by a positive rho value $(\rho=+2.6)$ determined by Hammett analysis. DFT calculations predict activation parameters that are consistent with experiment $\left(\Delta \mathrm{G}_{\text {calc }}^{\neq}=23.4 \mathrm{kcal} \mathrm{mol}^{-1}\right.$ compared to $\left.\Delta \mathrm{G}_{\text {exp }}^{\neq}=21.9 \mathrm{kcal} \mathrm{mol}^{-1}\right)$. Additionally, computed Hammett analyses are in good agreement with the observed acceleration of the reaction rate by electronwithdrawing substituents on the aryl group.

\section{Conclusions and Outlook}

In conclusion, the outcome of the reaction of aryl halides with a $\mathrm{Ni}(0)$ center strongly depends on the choice of supporting ligand. In this short perspective, we highlighted recent studies us-

(A)

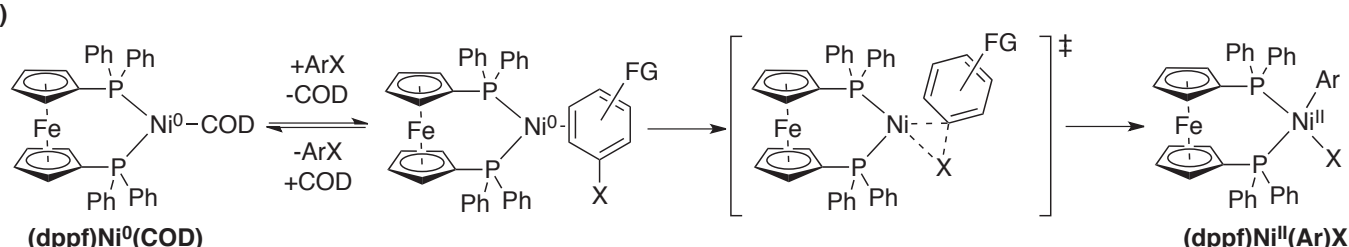

Scheme 4. Nelson's mechanistic proposal for the oxidative addition of aryl halides to (dppf) $\mathrm{Ni}^{0}(\mathrm{COD})$.

(B)

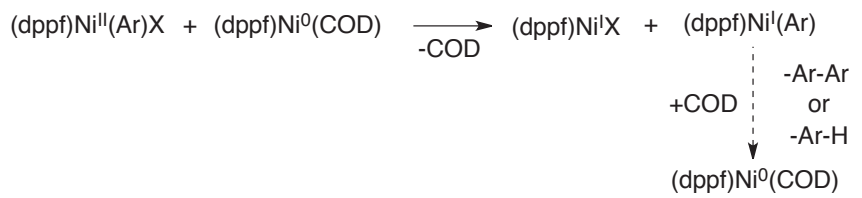

\section{Tridentate Phosphine Ligands}

The computational results discussed above highlighted the higher reactivity of tris(phosphine) $\mathrm{Ni}(0)$ complexes for $\mathrm{S}_{\mathrm{N}}$ 2-like oxidative addition. We reasoned that a tridentate phosphine could favor the oxidative addition over the halogen atom abstraction, and possibly also stabilize the Ni(II) aryl halide complexes in solution, preventing its decomposition by comproportionation. Using this hypothesis as a starting point, we recently reported a combined experimental and computational mechanistic study of the oxidative addition of aryl halides to a $\mathrm{Ni}(0)$ center bearing the tridentate ligand $\mathrm{PPP}^{p-\text { tol }}\left(\mathrm{PPP}^{p \text {-tol }}=\operatorname{bis}(2\right.$-bis $(p$-tolyl $)$ phosphinophenyl)-phenylphosphine). ${ }^{[21]}$ The reaction between $\left(\mathrm{PPP}^{\mathrm{p} \text {-tol }}\right) \mathrm{Ni}^{0}(\mathrm{BPI})(\mathrm{BPI}=$ benzophenone imine, a labile coligand) and aryl halides cleanly produced stable pentacoordinated $\left(\mathrm{PPP}^{\mathrm{p} \text {-tol }}\right) \mathrm{Ni}^{\mathrm{II}}(\mathrm{Ar}) \mathrm{X}$ complexes (Scheme 5). The X-ray crystal structure analysis showed a trigonal bipyramidal structure with a facial coordination for the tridentate ligand, an axial aryl ligand and an equatorial halide ligand. This geometry contrasts with the square-planar geometry observed for the overwhelming majority of phosphine-supported aryl-Ni(II) species. A kinetic study of ing phosphine ligands, focusing on the effect of the denticity of the ligand. These studies highlight how the selectivity between $\mathrm{Ni}^{\mathrm{II}}$ and $\mathrm{Ni}^{\mathrm{I}}$ products is affected by the supporting ligand, which is of importance for the development of efficient cross-coupling catalysts relying on two-electron mechanisms. When monodentate phosphines are used, a non-selective mixture of $\mathrm{Ni}^{\mathrm{II}}$ and $\mathrm{Ni}^{\mathrm{I}}$ species is often produced by parallel mechanisms: oxidative addition and halogen atom abstraction. Additionally, the stability of $\left[\mathrm{Ni}^{\mathrm{II}}\left(\mathrm{PR}_{3}\right)_{2}(\mathrm{Ar}) \mathrm{X}\right]$ species in solution is compromised by the lability of the phosphine ligand. In the case of bidentate phosphines, clean $\mathrm{Ni}^{\mathrm{II}}$ complexes can be obtained with electron-rich phosphines. For complexes bearing the widely used dppf ligand, the oxidative addition of aryl halides to the $\mathrm{Ni}(0)$ center is thought to proceed through a three-center, concerted transition state, but the stability of the resulting complexes (dppf)NiI $(\mathrm{Ar}) \mathrm{X}$ depends on the steric hindrance of the aryl ligand to avoid the fast formation of (dppf)Ni ${ }^{I} X$ complexes by comproportionation. Finally, the use of pincer triphosphine ligand $\mathrm{PPP}^{p \text {-tol }}$ selectively leads to the production of unusual pentacoordinate $\left(\mathrm{PPP}^{p-\text { tol }}\right) \mathrm{Ni}^{\mathrm{II}}(\mathrm{Ar}) \mathrm{X}$ displaying a high stability in solution. Further applications of this
Scheme 5. Oxidative addition of

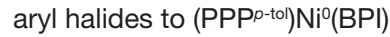
producing pentacoordinated (PPP $^{\text {-tol }) N i "}(\mathrm{Ar}) \mathrm{X}$ complexes.
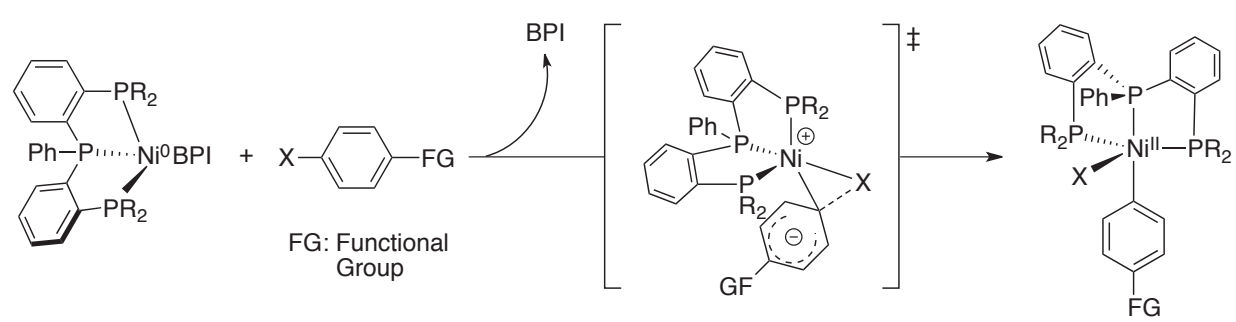

(PPPp-tol)Nill(Ar)X 
coordination motif for the development of efficient catalysts and their mechanistic understanding are currently under investigation in our laboratory.

\section{Acknowledgements}

This project has received funding from the European Research Council (ERC) under the European Union's Horizon 2020 research and innovation programme (grant agreement No 715060).

Received: April 20, 2020

[1] J. A. Labinger, Organometallics 2015, 34, 4784.

[2] A. Behr, P. Neubert, 'Applied Homogeneous Catalysis' Wiley-VCH: Weinheim, 2012.

[3] B. Rosen, K. W. Quasdorf, D. A. Wilson, N. Zhang, A.-M. Resmerita, N. K. Garg, V. Percec, Chem. Rev. 2011, 111, 1346.

[4] J. B. Diccianni, T. Diao, Trends in Chemistry 2019, 1, 830

[5] V. Ananikov, ACS Catal. 2015, 5, 1964.

[6] X. Hu, Chem. Sci. 2011, 2, 1867.

[7] M. M. Beromi, A. Nova, D. Balcells, A. M. Brasacchio, G. W. Brudvig, L. M. Guard, N. Hazari, D. J. Vinyard, J. Am. Chem. Soc. 2017, 139, 922.

[8] S. Ge, R. A. Green, J. F. Hartwig, J. Am. Chem. Soc. 2014, 136, 1617.

[9] G. Yin, I. Kalvet, U. Englert, F. Schoenebeck, J. Am. Chem. Soc. 2015, 137, 4164.

[10] N. Hazari, P. R. Melvin, M. M. Beromi, Nat. Rev. Chem. 2017, 1, No. 0025.

[11] M. M. Beromi, G. Banerjee, G. W. Brudvig, N. Hazari, B. Q. Mercado, ACS Catal. 2018, 8, 2526.
[12] C.-Y. Lin, P.P. Power, Chem. Soc. Rev. 2017, 46, 5347.

[13] T. T. Tsou, J. K. Kochi, J. Am. Chem. Soc. 1979, 101, 6319.

[14] A. Manzoor, P. Wienefeld, M. C. Baird, P. H. M. Budzelaar, Organometallics 2017, 36, 3508

[15] I. Funes-Ardoiz, J. D. Nelson, F. Maseras, Chem.-Eur. J. 2017, 23, 16728.

[16] G. G. Dubinina, W. W. Brennessel, J. L. Miller, D. A. Vicic, Organometallics $\mathbf{2 0 0 8}, 27,3933$

[17] E. Nicolas, A. Ohleier, F. D'Accrisco, A.-E. Pécharman, M. Demange, P. Ribagnac, J. Ballester, C. Gosmini, N. Mézailles, Organometallics 2008, 27 , 3933.

[18] J. B. Diccianni, J. Katigbak, C. Hu, T. Diao, J. Am. Chem. Soc. 2019, 141, 1788.

[19] S. Bajo, G. Laidlaw, A. R. Kennedy, S. Sproules, D. J. Nelson, Organometallics 2017, 36, 1662.

[20] J. Chatt, B. L. Shaw, J. Chem. Soc. 1960, 1718.

[21] P. M. Pérez-García, A. Darù, A. R. Scheerder, M. Lutz, J. N. Harvey, M.-E. Moret, Organometallics 2020, 39, 1139.

\section{License and Terms}

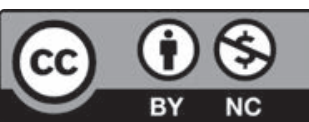

This is an Open Access article under the terms of the Creative Commons Attribution License CC BY_NC 4.0. The material may not be used for commercial purposes.

The license is subject to the CHIMIA terms and conditions: (http:// chimia.ch/component/sppagebuilder/?view = page\&id=12).

The definitive version of this article is the electronic one that can be found at doi:10.2533/chimia.2020.495. 